\title{
Igualdade de género e governação cooperativa em Portugal- uma análise jurídica e fática
}

\author{
Deolinda Meira \\ P.Porto/CEOS.PP/ISCAP \\ Ana Luisa Martinho \\ P.Porto/CEOS.PP/ISCAP \& Associação A3S
}

Recibido: 28-12-2018

Aceptado: 15-02-2019

Sumário: 1. Introdução. 2. Identidade Cooperativa e igualdade de género. 3. O objeto das cooperativas e a afirmação da igualdade de género. 4. A admissão dos membros potencialmente condicionada mas nunca discriminatória. 5. Governação cooperativa e igualdade de género. 6 . Igualdade de género e responsabilidade social da empresa. 7 . Tendências de igualdade de género nas cooperativas portuguesas. 8. Conclusões. Bibliografia.

Resumo: Este estudo demonstra que há uma conexão profunda entre o regime jurídico das cooperativas, que se baseia num conjunto de princípios e valores definidos pela Aliança Cooperativa Internacional e que integram o conceito de identidade cooperativa, e a igualdade de género. A governação democrática, que carateriza as cooperativas, impõe um regime de representação equilibrada entre mulheres e homens nos órgãos de administração e de fiscalização das cooperativas. No entanto, os dados fornecidos pelo Portal de Credenciação da CASES evidenciam uma representação desequilibrada. Impõe-se a adoção pelas cooperativas, por via estatutária ou regulamentar, de medidas positivas, tais como as quotas de género, que assegurem uma representação equilibrada entre homens e mulheres nos órgãos das cooperativas.

Palavras-Chave: cooperativa, igualdade de género, identidade cooperativa, princípios cooperativos, quotas de género.

\begin{abstract}
This study shows that there is a deep connection between the legal regime of cooperatives, which is based on a set of principles and values defined by the International Cooperative Alliance and that integrate the concept of cooperative identity, and gender equality.Democratic governance, which characterizes cooperatives, imposes a regime of balanced representation between women and men in the management and supervisory bodies of cooperatives. However, the data provided by CASES Credential Portal shows an unbalanced representation. It is necessary to adopt positive measures, such as gender quotas, which ensure a balanced representation between men and women in cooperative bodies.
\end{abstract}

Keywords: cooperative, gender equality, cooperative identity, cooperative principles, gender quotas. 


\section{Introdução}

A promoção da igualdade de género faz parte da história do movimento cooperativo internacional.

A Rochdale Society of Equitables Pioneers, de 1844, considerada a pioneira das cooperativas de consumo, contemplava, nos seus estatutos, entre outros, o princípio da igualdade de admissão de homens e mulheres, e de participação na atividade da cooperativa.

Efetivamente, os valores e princípios que regem o funcionamento das cooperativas tornam estas entidades especialmente sensíveis a questões relacionadas com práticas que promovam a igualdade de género, reprimindo atos discriminatórios ${ }^{1}$. A própria Aliança Cooperativa Internacional $(\mathrm{ACl})$, na sua Declaração do Dia Internacional da Mulher (2018), reconheceu a capacidade das cooperativas contribuírem para o empoderamento das mulheres e promoverem a igualdade de género no seu âmbito, designadamente no acesso a cargos de liderança ${ }^{2}$. Por outro lado, as mulheres têm vindo a descobrir, nas cooperativas, opções atrativas de participação, seja para alcançar as suas aspirações empresariais, seja como forma de aceder a produtos e serviços de que necessitam, seja como modo de participar numa empresa que baseia a sua filosofia em valores e princípios que proporcionam uma maior igualdade de oportunidades no que diz respeito ao acesso ao emprego ou mesmo ao acesso a cargos de administração e de fiscalização, comparativamente com outras entidades que operam no mercado ${ }^{3}$.

Em Portugal, o direito cooperativo contribuiu, historicamente, para a afirmação da igualdade de género. De facto, a primeira lei cooperativa, conhecida por Lei Basilar do Cooperativismo, de 2 de julho de 1867, no seu art. $7 .{ }^{\circ}$, que regulava a qualidade de membro da sociedade cooperativa, determinava que «todas as pessoas, sem distinção de sexo, maiores de 14 anos, podem ser sócios, satisfazendo às condições determinadas nos estatutos». Esta disposição reconhece às muIheres a capacidade de gozo para serem membros de cooperativas. Por sua vez, o $\S 10 .^{\circ}$ concede o direito de voto, independentemente do

1 V., neste sentido, RIBAS BONET, M. A. \& SAJARDO MORENO, A, «La desigual participación de hombres y mujeres en la economía social: teorías explicativas», CIRIECEspaña, Revista de Economía Pública, Social y Cooperativa, N. 50, 2004, p. 92 e ss..

2 Disponível em https://www.aciamericas.coop/Declaracion-de-la-Alianza-por-el-DiaInternacional-de-la-Mujer-2018.

3 V. SENENT VIDAL, M. J., «¿Cómo pueden aprovechar las cooperativas el talento de las mujeres? Responsabilidad social empresarial e igualdad real», REVESCO, N. ${ }^{\circ} 105$, 2011, p. 58 e ss.. 
sexo do membro que vota. Num tempo em que o voto estava vedado às mulheres, vivendo-se uma clara discriminação de género, a legislação cooperativa reconhecia o direito de voto às mulheres ${ }^{4}$.

As desigualdades de género, no contexto mais amplo de Portugal, estão presentes em várias áreas, com especial destaque para as dimensões do trabalho e da tomada de decisão. De acordo com o mais recente relatório sobre a Igualdade de Género em Portugal (CIG, 2017), especificamente no campo do trabalho, as taxas de emprego feminino permanecem abaixo das taxas de emprego masculinas (com uma diferença de 6,8 pontos percentuais). Em relação à taxa de desemprego, 2016 constituiu uma mudança, já que a taxa foi idêntica para homens e mulheres $(11,2 \%)$, ao contrário do que se verificava até então ${ }^{5}$.

As desigualdades de género no mercado de trabalho ainda constituem uma realidade significativa, sobretudo no que toca à diferenciação salarial. De acordo com os dados mais recentes, os salários médios para as mulheres são 15,8\% mais baixos do que para os homens. Isto significa que a disparidade salarial em Portugal corresponde a uma perda de 58 dias de trabalho remunerado para as mulheres. Tem havido um grande investimento em políticas para promover a igualdade de género. Assim, a recente Lei n. ${ }^{\circ} 60 / 2018$, de 21 de agosto, que entrará em vigor em 2019, prevê medidas para promover igual remuneração para trabalho igual.

Em relação à igualdade de género na tomada de decisões, em 2012, a Comissão Europeia propôs ao Estados-Membros a adoção de legislação que permitisse alcançar um objetivo de $40 \%$ do sexo subrepresentado (maioritariamente feminino) em cargos de administração e de fiscalização em empresas cotadas, excecionando desta medida as pequenas e médias empresas. Seguindo essa recomendação, em Portugal, em 23 de junho de 2017, foi aprovada, na Assembleia da República, a Lei n. ${ }^{\circ}$ 62/2017, que entrou em vigor em 1 de agosto, e que consagrou um regime de representação equilibrada entre mulheres e homens nos órgãos de administração e de fiscalização das empresas do setor público e das empresas cotadas.

Apesar desta crescente atenção política, segundo dados de 2017 da Comissão para a Igualdade de Género e Cidadania (CIG), as mulheres estão sub-representadas nos cargos de direção de topo e de direção executiva, designadamente com uma clara sub-representação nos con-

${ }^{4}$ MEIRA, D. \& RAMOS, M. E., «Lei Basilar das Cooperativas. Memórias de uma lei precursora e contraditória», ROA, Ano 77, 2017, p. 89 e ss..

5 Disponível em https://www.cig.gov.pt/wp-content/uploads/2017/07/AF_CIG_FactSheet.pdf 
selhos de administração das empresas. Em abril de 2016, a presença de mulheres nos conselhos de administração das empresas do PSI 20, em Portugal, continuava a ser de 14\% (9\% em 2015) e a dos homens de $86 \%$. Na UE28, a média é de $23 \%$ para as mulheres e $77 \%$ para os homens. Isto significa que a situação internacional e nacional não mudou significativamente nos últimos anos.

Este estudo assenta na constatação de que há uma conexão profunda e íntima entre o regime jurídico das cooperativas, que se baseia num conjunto de princípios e valores definidos pela Aliança Cooperativa Internacional e que integram o conceito de identidade cooperativa, e a igualdade de género ${ }^{6}$. Assim, partindo do enquadramento jurídico das cooperativas, pretende-se aferir se existe, na prática cooperativa, uma efetiva igualdade de género no acesso aos cargos de administração e de fiscalização das cooperativas portuguesas.

Veremos que o valor da igualdade é um valor estruturante do regime jurídico das cooperativas, em estrita ligação com os princípios cooperativos, com particular destaque para os princípios da gestão democrática, da adesão voluntária e livre e do interesse pela comunidade.

Estamos a reportar-nos a uma igualdade formal, que resulta da legislação cooperativa, dos estatutos e dos regulamentos internos da cooperativa. Para além desta, interessa-nos averiguar se existe uma igualdade de género construída.

São, por isso, duas as questões a que pretendemos responder neste estudo, a saber:

1. Em que medida é que o regime jurídico das cooperativas contribui para a construção e reforço de relações de género baseadas na ideia de paridade ou de equilíbrio?

2. Existe uma representação equilibrada de homens e mulheres nos cargos de administração e fiscalização nas cooperativas portuguesas?

A resposta a estas questões assentará, em termos metodológicos, numa pesquisa bibliográfica, na análise da legislação que enquadra esta temática e, ainda, na análise documental da Base de Dados do Portal de Credenciação, disponibilizada pela CASES-Cooperativa António Sérgio para a Economia Social. Esta fonte secundária representa 749 cooperativas com credencial válida à data de 30 de novembro de

6 V., neste sentido, SENENT VIDAL, M. J., «Aspectos de la perspectiva de género en la regulación jurídica de las cooperativas», In Ferraz Teixeira, M. \& Ferraz Teixeira, M. (eds.), O Pensamento Feminino na Construção do Direito Cooperativo, Brasília: Vincere Editora, p. 229 e ss. 
2018. A Base de Dados resulta do preenchimento por parte das próprias cooperativas de informação relativa ao exercício de 2017 quanto ao número de membros da Mesa da Assembleia-Geral, número de membros do órgão de administração; número de membros do órgão de fiscalização, com dados desagregados por sexo.

\section{Identidade Cooperativa e igualdade de género}

As cooperativas têm uma singularidade própria, apelidada pela Aliança Cooperativa Internacional $(\mathrm{ACl})$ de «Identidade Cooperativa». Este conceito definido pela $\mathrm{ACl}$, em Manchester, em 1995, assenta numa Noção de Cooperativa, num conjunto de princípios (os Princípios Cooperativos) e num conjunto de valores (os Valores Cooperativos), que enformam aqueles princípios ${ }^{7}$.

A ACl estabeleceu que "uma cooperativa é uma associação autónoma de pessoas unidas voluntariamente para prosseguirem as suas necessidades e aspirações comuns, quer económicas, quer sociais, quer culturais, através de uma empresa comum e democraticamente controlada».

Os valores que funcionam como uma estrutura ética dos princípios cooperativos são: i) os valores de autoajuda, responsabilidade individual, democracia, igualdade, equidade e solidariedade, nos quais assenta a atividade das cooperativas enquanto organizações; ii) os valores da honestidade, transparência, responsabilidade social e altruísmo que se dirigem ao comportamento individual dos cooperadores enquanto tais ${ }^{8}$.

Os princípios cooperativos, que refletem o que a cooperativa tem de mais específico, contendo o essencial da Identidade Cooperativa9 ${ }^{9}$, são sete: adesão voluntária e livre; gestão democrática pelos membros; participação económica dos membros; autonomia e independência;

$7 \mathrm{~V}$. FICl, A., "Cooperative Identity and the Law», European Business Law Review, n. ${ }^{\circ} 24,2013$, pp. 37-64.

8 V. MORENO, J. L., "Los valores según la Alianza Cooperativa Internacional (ACI)», CIRIEC-España, Revista Jurídica de Economía Social y Cooperativa, n. ${ }^{\circ} 25,2014$, pp. 371-393.

9 V. NAMORADO, R., Os Princípios Cooperativos, Coimbra, Fora do Texto, 1995, passim; e LEITE, J. S., Princípios Cooperativos, Lisboa, Imprensa Nacional Casa da Moeda, 2012; MEIRA, D. A. \& RAMOS, M. E., «Os princípios cooperativos no contexto da reforma do Código Cooperativo português», CIRIEC-España, Revista jurídica de economía social y cooperativa, N. ${ }^{\circ} 27,2015$, pp. 401-428. 
educação, formação e informação; intercooperação; e interesse pela comunidade.

No ordenamento português, os princípios cooperativos são acolhidos pela Constituição da República Portuguesa (CRP) ${ }^{10}$.

Assim, o art. 61., n. 2, da CRP dispõe que «a todos é reconhecido o direito à livre constituição de cooperativas, desde que observados os princípios cooperativos». Por sua vez, o art. $82 .^{\circ}, \mathrm{n} .{ }^{\circ} 4$, al. a), da CRP consagra que o subsetor cooperativo «abrange os meios de produção possuídos e geridos por cooperativas, em obediência aos princípios cooperativos».

A CRP não identifica os princípios cooperativos, sendo feita uma remissão expressa para os princípios definidos pela $A C l$ e que estão descritos no art. 3. ${ }^{\circ}$ do Código Cooperativo português (CCoop) ${ }^{11}$. Segundo Rui Namorado esta posição adotada na CRP põe à mercê das decisões da $\mathrm{ACl}$ a conformação do setor cooperativo português, pelo que, quando a $\mathrm{ACl}$ alterar os princípios, será a nova opção que passará a vigorar na ordem jurídica portuguesa ${ }^{12}$.

Nas palavras de Gomes Canotilho e Vital Moreira «As «cooperativas» que não respeitem estes princípios cooperativos não são verdadeiras cooperativas no sentido constitucional, não podendo gozar portanto das respetivas garantias» ${ }^{13}$.

No plano da legislação ordinária, o CCoop associa a noção de cooperativa (art. 2. ${ }^{\circ}$ do CCoop) à necessária obediência aos princípios cooperativos. Assim, nos termos do n. 1 do art. $2 .^{\circ}$ do CCoop, serão cooperativas as «pessoas coletivas autónomas, de livre constituição, de capital e composição variáveis, que, através da cooperação e entreajuda dos seus membros, com obediência aos princípios cooperativos, visam, sem fins lucrativos, a satisfação das necessidades e aspirações económicas, sociais ou culturais daqueles». Deste modo, o regime jurídico das cooperativas em Portugal deve assentar na observância de tais princípios cooperativos, enunciados no art. $3 .^{\circ}$ do CCoop.

Neste contexto, no ordenamento português, a consagração jurídico-constitucional dos princípios cooperativos, nos arts. $61 .{ }^{\circ},{ }^{\circ} .^{\circ} 2$

10 Sobre o acolhimento jurídico-constitucional dos princípios cooperativos, v. MEIRA, D. A., "O quadro jurídico-constitucional do cooperativismo em Portugal», Cooperativismo e Economía Social, n. ${ }^{\circ}$ 33, 2011, pp. 31-46.

11 Lei n. ${ }^{\circ} 119 / 2015$, de 31 de agosto, com as alterações constantes da Lei n. ${ }^{\circ} 66 / 2017$, de 9 de agosto.

12 V. NAMORADO, R., As Cooperativas. Empresas que não são Associações, Faculdade de Economia da Universidade de Coimbra, 1999, p. 20.

13 CANOTILHO, G. \& MOREIRA, V., Constituição da República Portuguesa anotada, vol. I, Coimbra, Coimbra Editora, 2007, p. 793. 
e $82 .^{\circ}$, n. $^{\circ} 4$, al. a) da CRP, confere-lhes uma força vinculativa e conformadora própria das normas jurídico-constitucionais. Segundo Gomes Canotilho e Vital Moreira, "Sendo a Constituição a norma suprema do país, todas as demais normas a devem respeitar» ${ }^{14}$. Isto significa que 0 legislador ordinário está juridicamente obrigado a respeitar o sentido dos princípios cooperativos no momento em que produz normas jurídicas relativas ao regime jurídico das cooperativas. Em consequência, os atos legislativos do legislador ordinário que desrespeitem os princípios cooperativos estarão feridos de inconstitucionalidade (art. 277. ${ }^{\circ}, \mathrm{n} .{ }^{\circ} 1$ da (RP15).

Na mesma linha, o CCoop dispõe que o desrespeito da cooperativa pelos princípios cooperativos, no seu funcionamento, constituirá causa de dissolução da mesma [al. h) do n. ${ }^{\circ} 1$ do art. $112 .^{\circ}$ do CCoop]. Trata-se de uma causa de dissolução compulsiva por via judicial.

Cabe à Cooperativa António Sérgio para a Economia Social (CA$\mathrm{SES})$, cooperativa de interesse público que congrega o Estado e diversas organizações da economia social, criada pelo Decreto-Lei n. ${ }^{\circ} 282 / 2009$, de 7 de outubro, no exercício das suas funções de supervisão do setor cooperativo em Portugal (arts. $115 .^{\circ}$ a $118 .^{\circ}$ do CCoop), fiscalizar, nos termos da lei, a utilização da forma cooperativa, com respeito pelos princípios cooperativos, e normas relativas à sua constituição e funcionamento. Para o efeito, as cooperativas estão obrigadas a remeter à CASES cópia dos atos de constituição e de alteração dos estatutos, dos relatórios anuais de gestão, dos documentos anuais de prestação de contas e do balanço social. Assim, a CASES deverá requerer, através do Ministério Público, junto do tribunal competente, a dissolução das cooperativas que não respeitem, no seu funcionamento, os princípios cooperativos $^{16}$.

Deste conceito de identidade cooperativa, resulta a afirmação de um ideal democrático de igualdade, que contraria o estabelecimento de discriminações em função do género. Efetivamente, os valores da democracia, igualdade, equidade e solidariedade são contrários a qualquer forma de discriminação. Assim, a igualdade implica que os direitos e deveres devem beneficiar e obrigar todos os cooperadores, sejam homens ou mulheres.

${ }^{14}$ CANOTILHO, G. \& MOREIRA, V., Constituição da República Portuguesa anotada, cit., p. 881.

15 Esta norma estabelece que «São inconstitucionais as normas que infrinjam o disposto na Constituição ou os princípios nela consignados».

16 V. MEIRA, D.A. \& RAMOS, M.E., "Os princípios cooperativos no contexto da reforma do Código Cooperativo português», cit., pp. 407-409. 
Tomando por referência a doutrina e a jurisprudência constitucionais, a propósito do princípio da igualdade constitucionalmente consagrado, consideramos que, também no âmbito cooperativo, deverá distinguir-se três dimensões neste ideal democrático de igualdade: a proibição do arbítrio (tratar como igual o que é igual e como diferente o que é diferente); a proibição de discriminação; e a obrigação de diferenciação (adoção de discriminações positivas de forma a compensar as eventuais desigualdades) ${ }^{17}$.

Por outro lado, e tal como veremos de seguida, da análise dos princípios cooperativos, que orientam o funcionamento e a atividade das cooperativas, resulta a necessária adoção de políticas e de práticas cooperativas assentes na igualdade de género ${ }^{18}$.

\section{O objeto das cooperativas e a afirmação da igualdade de género}

No objeto social das cooperativas articulam-se duas dimensões: a dimensão económica e a dimensão social.

Esta articulação resulta da própria noção de cooperativa constante do art. 2. ${ }^{\circ}$ do CCoop - nos termos do qual o objeto da cooperativa se traduzirá na satisfação, sem fins lucrativos, das necessidades económicas, sociais ou culturais dos seus membros, tendo por referência um modo de gestão da empresa cooperativa que assentará na obediência aos princípios cooperativos, e na cooperação e entreajuda dos membros.

A dimensão económica está presente no segmento do n. ${ }^{\circ} 1$ do art. 2. ${ }^{\circ}$ do CCoop, quando se refere que faz parte do escopo cooperativo "a satisfação das necessidades e aspirações económicas» dos cooperadores.

No entanto, o objeto social da cooperativa não se circunscreve à satisfação das necessidades dos seus membros, devendo atender, igualmente, aos interesses da comunidade onde a cooperativa desenvolve a sua atividade.

Neste sentido, o princípio do interesse pela comunidade, que aparece enunciado no art. $3 .^{\circ}$ do CCoop, dispõe que «as cooperativas trabalham para o desenvolvimento sustentável das suas comunidades, através de políticas aprovadas pelos membros».

17 FERTUZINHOS, S., «Fundamentos constitucionais da igualdade de género», Sociologia, Problemas e Prática, 2016, p. 56.

18 V., neste sentido, SENENT VIDAL, M.J., «Aspectos de la perspectiva de género en la regulación jurídica de las cooperativas», cit., pp. 230-232. 
Assim, ainda que centradas nas necessidades dos seus membros, as cooperativas trabalham para conseguir o desenvolvimento sustentável das suas comunidades, segundo os critérios aprovados por estes.

A incorporação de membros provenientes do âmbito territorial onde a cooperativa realiza maioritariamente a sua atividade foi uma constante neste tipo organizacional, cuja finalidade última seria a da satisfação das necessidades sentidas pela comunidade, aparecendo a cooperativa, deste modo, como entidade geradora de empregos estáveis (principalmente porque as cooperativas, em virtude do seu forte enraizamento a nível local, desenvolvem atividades que, pela sua própria natureza, não são suscetíveis de serem deslocalizáveis), sem discriminação de género no acesso à qualidade de membro e fomentadora de um espírito empreendedor.

Assim, as cooperativas terão a particular responsabilidade de assegurar que o desenvolvimento das suas comunidades seja económica, social e culturalmente sustentado.

Deste princípio decorrerá, portanto, o envolvimento das cooperativas no contexto social, cabendo aos cooperadores a escolha das políticas através das quais esse envolvimento se concretizará.

Um outro princípio de enorme relevância para a sustentação da afirmação de que o objeto da cooperativa abrange o desenvolvimento de atividades com uma dimensão social relevante, será o princípio da educação, formação e informação (art. 3. ${ }^{\circ}$ do CCoop).

Diz o legislador que "as cooperativas promoverão a educação e a formação dos seus membros, dos representantes eleitos, dos dirigentes e dos trabalhadores, de modo que possam contribuir eficazmente para o desenvolvimento das suas cooperativas. Elas devem informar o grande público, particularmente os jovens e os líderes de opinião, sobre a natureza e as vantagens da cooperação» (art. 3. ${ }^{\circ}$ do (Coop).

Este princípio realça a obrigação de as cooperativas, na sua atividade, assegurarem a educação e formação, quer dos seus membros, quer dos titulares dos seus órgãos eleitos, quer dos seus administradores, quer dos seus trabalhadores.

Além disso, este princípio abrange o dever de informar o público em geral, visando sensibilizá-los para a natureza e benefícios da cooperação, o que poderá fomentar novas adesões, e sobretudo adesões conscientes.

Refira-se, finalmente, que este princípio se concretiza, no CCoop, através da consagração de uma reserva obrigatória «para a educação cooperativa e a formação cultural e técnica dos cooperadores, dos trabalhadores da cooperativa e da comunidade» (art. 70. ${ }^{\circ}$ ). 
A constituição deste tipo de reserva, com esta finalidade, significa que a cooperativa é não só uma organização económica, mas também uma organização com finalidades pedagógicas e sociais.

Esta reserva constitui uma das notas mais distintivas da empresa cooperativa relativamente às restantes formas de empresa. Cria-se um património afetado a fins sociais, do qual beneficiarão os próprios cooperadores, os trabalhadores da cooperativa e o meio social ${ }^{19}$.

Esta dupla dimensão - social e económica - do objeto das cooperativas torna-as um veículo ideal para a afirmação da igualdade de género. Assim, tendo em conta o caráter vinculativo dos princípios cooperativos no ordenamento português, recai sobre as cooperativas o dever de educar, formar e informar, quer os membros, quer os trabalhadores, quer os titulares dos órgãos, quer a comunidade em que a cooperativa está inserida, quanto à necessária igualdade de oportunidades e de tratamento no que se refere ao acesso à qualidade de cooperador ou ao acesso à qualidade de titular dos órgãos. Acresce que não pode a cooperativa, em razão do género, privilegiar, beneficiar, prejudicar, privar de qualquer direito ou isentar de qualquer dever os membros, aspirantes a membros ou trabalhadores não membros.

\section{A admissão dos membros potencialmente condicionada, mas nunca discriminatória}

Nas cooperativas de $1 .^{\circ}$ grau, o acesso à condição de cooperador pode ocorrer por três vias: pela participação inicial na constituição da cooperativa (cooperador fundador); pelo posterior ingresso na cooperativa constituída; ou pela transmissão inter vivos ou mortis causa de títulos de capital.

Em qualquer dos casos, o candidato a cooperador, que poderá ser uma pessoa singular ou coletiva, deverá preencher "os requisitos e condições previstos no presente Código, na legislação complementar aplicável aos diversos ramos do setor cooperativo e nos estatutos da cooperativa» (art. 19. ${ }^{\circ}$, n. $^{\circ} 1$, do CCoop).

A definição de tais requisitos e condições de admissão está intimamente ligada ao escopo mutualístico das cooperativas. Como vimos, a título principal, as cooperativas visam "sem fins lucrativos, a satisfa-

19 -Sobre este princípio e reserva, v. MEIRA, D.A., «Reflexões em torno do regime jurídico da reserva de educação e formação cooperativas», In Ferraz Teixeira, M. \& Ferraz Teixeira, M. (eds.), O Pensamento Feminino na Construção do Direito Cooperativo, Brasília, Vincere Editora, pp. 56-72. 
ção das necessidades económicas, sociais e culturais» (art. $2^{\circ}{ }^{\circ}$ n. ${ }^{\circ} 1$, do (Coop) dos seus membros, que são os destinatários principais das atividades que estas levam a cabo. A cooperativa constitui-se «por e para os membros», com os quais opera no âmbito da atividade que a eles se dirige e na qual participam cooperando. Esta participação traduzirse-á num intercâmbio recíproco de prestações entre a cooperativa e os cooperadores, prestações essas que são próprias do objeto social das cooperativas. Deste modo, o aspirante a cooperador deverá estar apto a participar na atividade da cooperativa, enquanto consumidor, fornecedor ou trabalhador, nos termos estatutários.

Assim, o cooperador, diversamente do sócio de uma sociedade comercial, não estará apenas sujeitado à obrigação de entrada para o capital social da cooperativa (art. 83. ${ }^{\circ}$ do CCoop) e eventual joia (art. 90. ${ }^{\circ},{ }^{\circ}{ }^{1}$, do CCoop), mas também, e principalmente, à obrigação de participar na atividade da mesma. Neste sentido, o art. 22. ${ }^{\circ}$, n. ${ }^{\circ} 2$, al. c), do CCoop estabeleceu que os cooperadores deverão "participar em geral nas atividades da cooperativa e prestar o trabalho ou serviço que lhes competir, nos termos estabelecidos nos estatutos».

Como já foi destacado, no desenvolvimento do seu objeto social, as cooperativas devem observar os princípios cooperativos (art. 2. , n. ${ }^{\circ} 1$, do CCoop).

De entre estes princípios destaca-se o Princípio da adesão voluntária e livre que aparece formulado, no art. $3 .^{\circ}$ do CCoop, nos seguintes termos: "As cooperativas são organizações voluntárias, abertas a todas as pessoas aptas a utilizar os seus serviços e dispostas a assumir a responsabilidade de membro, sem discriminações de sexo, sociais, políticas, raciais ou religiosas» 20 .

Deste princípio, que corresponde ao tradicional Princípio da porta aberta, decorre que: (i) a adesão deverá ser voluntária, uma vez que dependerá da vontade do cooperador; (ii) a adesão deverá ser aberta a todas as pessoas, desde que estas, como candidatas a cooperadores, preencham duas condições: a possibilidade de fruírem a utilidade própria da cooperativa e a aceitação das responsabilidades inerentes à filiação; (iii) a ninguém poderá ser recusada a entrada numa cooperativa sem uma razão objetiva, ou seja, sem uma razão que, pela sua própria natureza, possa significar uma qualquer discriminação (social, de género, racial, política ou religiosa $)^{21}$.

20 V. LEITE , J. S., Princípios Cooperativos, cit., p. 48 e ss.

21 V. GAMINDE EGIA, E., "Las altas de los/as socios/as en las sociedades cooperativas», Boletín de la Asociación de Derecho Cooperativo, n. ${ }^{\circ}$ 51, 2016, p. 191 e ss. 
Isto significa que, dado o fim mutualista da cooperativa, qualquer pessoa interessada - e que cumpra os requisitos de admissão exigidos estatutariamente - deverá poder ingressar como membro na cooperativa e beneficiar dos serviços que esta lhe oferece. Ou seja, para poder ingressar como membro na cooperativa, não será necessário adquirir a participação social de outro cooperador ou esperar que a cooperativa realize um aumento de capital22.

Assim, ter-se-á de verificar, em concreto, a aptidão do candidato a cooperador, quer para utilizar os serviços da cooperativa ou para desenvolver o trabalho que a integração na cooperativa implicará, quer para aceitar a cultura e valores cooperativos.

Deste modo, o candidato a cooperador não tem um direito de admissão sem limites ou condições, devendo, assim, falar-se de uma relatividade do Princípio da adesão voluntária e livre. Efetivamente, poderão existir limitações, quer condicionadas pela natureza específica dos interesses que os membros prosseguem em comum, quer baseadas em critérios objetivos - como, por exemplo: a cláusula profissional, pela qual só poderão ser cooperadores as pessoas que sejam proprietárias de determinado tipo de empresa ou que exerçam determinada profissão (v. g. as cooperativas de pesca servem sobretudo pescadores; as cooperativas de artesanato servem sobretudo artesãos); a cláusula de residência ou de âmbito geográfico (as cooperativas agrícolas servem aqueles que exerçam uma atividade agrícola em explorações localizadas na área geográfica da cooperativa); as razões relacionadas com o próprio sujeito (numa cooperativa de produção operária, só poderão adquirir a qualidade de cooperador trabalhador as pessoas singulares); uma concreta situação pessoal (ser aluno numa cooperativa de ensino);ou razões de natureza técnica, resultantes dos limites da dimensão da empresa.

O que não se permite são limitações arbitrárias ou discriminatórias. Nesta linha, Rui Namorado sustenta que «qualquer restrição à livre entrada de novos cooperadores deve resultar da própria natureza da cooperativa e não de um juízo arbitrário de rejeição, potencialmente discriminatório, por ser de mera incidência individual ${ }^{23}$.

O legislador estabeleceu que os estatutos de cada cooperativa deverão conter as "condições de admissão» dos membros [art. $16 .{ }^{\circ}, \mathrm{n}^{\circ} \mathrm{2}$, al. a), do CCoop $]^{24}$. Os estatutos da cooperativa poderão fazer depen-

22 V. MÜNKNER,H.-H., Co-operative Principles and Co-operative Law, 2nd, revised edition, Lit Verlag GmbH \& Co. KG Wien, Zurich, 2015, p. 96 e ss..

23 V. NAMORADO, R., Os Princípios Cooperativos, cit., 1995, p. 61.

24 V. MÜNCKNER, H.H., Nueve Lecciones de Derecho Cooperativo, Friedrich EbertStiftung, Marburg, 1982, p. 44 e ss.. 
der a admissão do cumprimento de requisitos razoáveis relacionados com o seu tipo e objetivos, mas sem discriminação de sexo, social, étnica, racial, política ou religiosa ou qualquer outra restrição artificial25.

\section{Governação cooperativa e igualdade de género}

O princípio da gestão democrática pelos membros consagra que "as cooperativas são organizações democráticas geridas pelos seus membros, os quais participam ativamente na formulação das suas políticas e na tomada de decisões. Os homens e as mulheres que exerçam funções como representantes eleitos são responsáveis perante o conjunto dos membros que os elegeram. Nas cooperativas de primeiro grau, os membros têm iguais direitos de voto («um membro, um voto»), estando as cooperativas de outros graus organizadas também de uma forma democrática» (art. 3. ${ }^{\circ}$ do CCoop).

A governação das cooperativas carateriza-se, deste modo, como uma governação democrática, evidenciada nos seguintes aspetos: a igualdade de tratamento dos cooperadores, independentemente da sua participação financeira e do género; a igualdade de direito de voto de todos os membros («um membro, um voto»); a eleição, pelos membros, dos titulares dos órgãos sociais, que terão de ser obrigatoriamente cooperadores.

A gestão democrática assenta na necessária participação ativa, por parte dos cooperadores, na definição das políticas da cooperativa e na tomada de decisões, participando nas assembleias gerais [arts. $33 .^{\circ}$, n. ${ }^{\circ} 2$, e $40 .^{\circ}$ do CCoop] e integrando os demais órgãos sociais da cooperativa ${ }^{26}$. Os titulares dos órgãos de administração e fiscalização são eleitos pela assembleia geral [al. a) do art. $38 .^{\circ}$ do CCoop] de entre os cooperadores ou, limitadamente, de membros investidores ( $n$. os 1 e 8 do art. 29. ${ }^{\circ}$ do (Coop), afastando-se, assim, a possibilidade de não membros poderem integrar este órgão. Segundo a doutrina cooperativa este mecanismo foi concebido pelo legislador para assegurar que os membros dos órgãos de administração e de fiscalização da coope-

$25 \mathrm{~V}$., neste sentido, $\mathrm{FICl}, \mathrm{A}$., "Chapter 1. Definition and Objetives of Cooperatives», In Fajardo,G., Fici, A., Henrÿ, H., Hiez, D., Meira, D., Münkner, H., and Snaith, I., Principles of European Cooperative Law. Principles, Commentaries and National Reports, Cambridge, Intersentia, p. 37 e ss. No mesmo sentido, VARGAS VASSEROT, C., «El principio cooperativo de puertas abiertas (Adhesión voluntaria y abierta). Tópico o realidad en la legislación y en la práctica societária», CIRIEC. Revista Jurídica de Economía Social y Cooperativa, n. ${ }^{\circ} 27,2015$, p. 156 e ss.

${ }_{26}$ V., neste sentido, HIEZ, D., Coopératives. Création, Organisation, Fonctionnement, Éditions Delmas, Daloz, 2013, p. 181. 
rativa centrariam a sua atuação no objetivo de promoção dos interesses dos membros. De facto, este mecanismo, ao permitir que os interesses dos cooperadores estejam diretamente representados nos órgãos de administração e de fiscalização, apresenta a vantagem de os titulares destes órgãos da cooperativa, pela sua própria experiência, terem permanentemente presentes os interesses dos cooperadores, não se desviando da finalidade principal da cooperativa ${ }^{27}$.

Esta governação democrática terá de ser representativa, pelo que se impõe um regime de representação equilibrada entre mulheres e homens nos órgãos de administração e de fiscalização das cooperativas.

A gestão democrática pelos membros assenta na regra da igualdade de direitos de voto - pelo menos nas cooperativas de primeiro grau (art. $40{ }^{\circ}$, n. $^{\circ} 1$, do CCoop) - , admitindo-se exceções para as cooperativas de segundo grau (art. $104 .^{\circ}$ do CCoop) e para as cooperativas que resultem da associação entre cooperativas ou entre cooperativas e pessoas coletivas de direito público (art. $8 .{ }^{\circ}$, n. $^{\circ} 3$, do CCoop).

Questão relevante é a de saber se será compatível com o princípio da gestão democrática a adoção de medidas de ação positiva, como as quotas de género, destinadas a atenuar a desigualdade fática no acesso feminino aos cargos de administração e fiscalização das cooperativas. Estas quotas de género, previstas na Lei n. ${ }^{\circ}$ 62/2017, de 1 de agosto, para as empresas públicas e as cotadas em bolsa, obrigam ao cumprimento de quotas mínimas de mulheres nos órgãos de administração e de fiscalização.

Estamos perante medidas que visam assegurar uma democracia paritária, através de uma participação equilibrada de mulheres e homens nos órgãos da cooperativa. Neste contexto, e tal como destaca Senent Vidal, e na ausência de uma posição legal expressa, o movimento cooperativo deve refletir sobre as medidas concretas a adotar para assegurar uma verdadeira democracia paritária, o que poderá passar pela imposição por via dos estatutos, dos regulamentos internos ou de deliberações dos órgãos da cooperativa, de quotas de género e/ou a obrigatoriedade da elaboração anual de planos para a igualdade ${ }^{28}$.

27 V. MÜNKNER, H.-H., Nueve Lecciones de Derecho Cooperativo, cit., p. 73; no mesmo sentido, destacando a potencial oposição entre os interesses dos cooperadores e dos gestores profissionalizados não membros, v. HIEZ, D., Coopératives. Création, Organisation, Fonctionnement, cit., p. 180; MEIRA, D.A. \& RAMOS, M.E., Governação e regime económico das cooperativas: estado da arte e linhas de reforma, Vida Económica, Porto, 2014, pp. 26 e ss.

28 V. SENENT VIDAL, M. J., «¿Cómo pueden aprovechar las cooperativas el talento de las mujeres? Responsabilidad social empresarial e igualdad real», cit., pp. 75-76. 
Todas estas medidas permitirão alcançar uma efetiva igualdade de tratamento e de oportunidades entre mulheres e homens, promovendo a eliminação da discriminação em função do género.

\section{Igualdade de género e responsabilidade social da empresa}

Como vimos, a governação das cooperativas não se restringe às suas relações internas. Por força dos princípios cooperativos, o paradigma da governação das cooperativas deverá estar alinhado com os princípios fundamentais da Responsabilidade Social da Empresa (RSE), baseando-se na adoção das melhores práticas no que respeita à organização, à igualdade de oportunidades, à inclusão social e ao desenvolvimento sustentável.

Cremos que, no que respeita às cooperativas, a RSE não é voluntária. Por outras palavras, atendendo ao enquadramento legal das cooperativas, designadamente ao facto de os órgãos sociais da cooperativa terem de atender, no desenvolvimento da sua atividade, ao princípio do interesse pela comunidade (art. $3 .^{\circ}$ do CCoop), se deverá questionar a existência de uma obrigação legal de os órgãos responsáveis pela administração da cooperativa terem o dever de integrar na sua atividade os valores fundamentais da RSE, dever esse que deverá estar sujeito a controlo, quer interno (a cargo da assembleia geral e do órgão de fiscalização), quer externo (a cargo da CASES) ${ }^{29}$. Assim se compreende que o órgão de administração da cooperativa tenha de elaborar um «balanço social», a aprovar em assembleia geral e a enviar para a CASES [al. c) do art. $116 .^{\circ}$ do CCoop], com o intuito de que the seja conferida credenciação, como prova da sua incorporação legal como cooperativa e funcionamento apropriado ${ }^{30}$.

Neste contexto, as cooperativas devem adotar práticas de responsabilidade social que satisfaçam as expetativas dos seus diversos membros, tais como promoção da igualdade entre mulheres e homens nos processos de admissão e de acesso aos órgãos, afastando critérios discriminatórios, adoção de critérios igualitários na distribuição de resulta-

29 V. MEIRA, D., «Cooperative social responsibility: A Intercultural Analysis», in Clara Sarmento (ed.), In Permanent Transit. Discourses and Maps of the Intercultural Experience, Cambridge Scholars Publishing, 2012, pp. 127-144.

30 V. MÖLLS, S.H. \& STEHR, A., "Control of success, monitoring and evaluation when spreading the message of the Blueprint», in S.H. MÖLLS, HANS-H. MÜNKNER (eds.), ICA Blueprint for a Co-operative Decade - a Critical Anallysis, Nomos, Marburg, 2015, pp. 93-111. 
dos e demais regalias definidas por lei, investimento em programas de promoção da igualdade, entre outros ${ }^{31}$.

\section{A participação das mulheres nos órgãos de administração e fiscalização das cooperativas portuguesas}

Em Portugal, e apesar do recente esforço de contabilização da realidade em termos de economia social, verifica-se ainda uma incipiência de dados sobre a situação da igualdade nas cooperativas nacionais. Com efeito, os dados expostos nas Contas Satélite para a Economia Social (INE, 2013 e 2016) não são apresentados de forma desagregada por sexo, o que inviabiliza uma leitura acerca das taxas de feminização nas diferentes famílias da economia social e na cooperativa em particular.

Apesar esta escassez de dados, analisamos a composição dos órgãos de governação nas seguintes cooperativas de cúpula: i) CASESCooperativa António Sérgio para a Economia Social; ii) Confagri-Confederação Nacional das Cooperativas Agrícolas e do Crédito Agrícola de Portugal, CCRL; iii) Confecoop-Confederação Cooperativa Portuguesa, CCRL; and iv) Fenacerci-Federação Nacional de Cooperativas de Solidariedade Social.

Tabela 1

\section{Composição dos órgãos sociais em cooperativas de cúpula}

\begin{tabular}{l|cc|cc|cc}
\hline & \multicolumn{2}{|c|}{$\begin{array}{c}\text { Direção / } \\
\text { Administração }\end{array}$} & \multicolumn{2}{c|}{ Mesa da Assembleia } & \multicolumn{2}{c}{ Conselho fiscal } \\
\cline { 2 - 7 } & $\mathrm{M}(\mathrm{n})$ & $\mathrm{H}(\mathrm{n})$ & $\mathrm{M}(\mathrm{n})$ & $\mathrm{H}(\mathrm{n})$ & $\mathrm{M}(\mathrm{n})$ & $\mathrm{H}(\mathrm{n})$ \\
\hline Cases & 3 & 2 & 0 & 3 & 0 & 3 \\
Confagri & 0 & 9 & 0 & 3 & 0 & 3 \\
Confecoop & 0 & 3 & 2 & 1 & 0 & 3 \\
Fenacerci & 3 & 2 & 1 & 2 & 2 & 1 \\
\hline Total & 6 & 16 & 3 & 9 & 2 & 10 \\
\hline
\end{tabular}

Fonte: websites da Cases, Confagri, Confescoop, Fenacerci (dados de 2018).

31 V. MARTíNEZ LEÓN, I. M.; ARCAS LARIO, N. \& GARCÍA HERNÁNDEZ, M., «La influencia del género sobre la responsabilidad social empresarial en las entidades de economía social», REVESCO, N. ${ }^{\circ}$ 105, 2011, pp. 143-172; ZURDO, R.P.; GARCÍA CENTENO, C.; GUTIÉRREZ FERNÁNDEZ, M. \& FERNÁNDEZ BARBERIS, G., «Responsabilidad social corporativa y género en los consejos de administración de las cooperativas de crédito españolas», Prisma Social, N. ${ }^{\circ}$ 10, junio-noviembre, 2013, pp. 332-360. 
Esta análise revela uma clara desigualdade de género, como pode ser observado na tabela 1. De facto, num total de 46 membros dos órgãos sociais, verificamos que apenas 11 são mulheres, o que representa apenas $23,9 \%$. Se olharmos para os dirigentes máximos da organização, observamos que apenas no caso da Fenacerci é possível encontrar uma Presidente.

Com base na já mencionada fonte secundária do Portal de Credenciação da CASES, procedemos à análise dos dados no que respeita à governação das cooperativas em função da variável «sexo dos membros» da Mesa da Assembleia-Geral, do órgão de administração e do órgão de fiscalização.

Existe uma média de 9,4 pessoas com funções nos três órgãos sociais - Mesa da Assembleia-Geral, órgãos de administração e órgãos de fiscalização- perfazendo um total de 7.022 pessoas nos órgãos sociais das 749 cooperativas, distribuídos entre 5.413 homens e 1.609 mulheres, correspondendo a $77,1 \%$ e $22,9 \%$ respetivamente. A distribuição de género pelos três órgãos sociais é equitativa, sendo que nos órgãos de administração existe uma menor percentagem de muIheres, com 22,1\%, seguindo-se os órgãos de fiscalização com 22,7\% e a Mesa da Assembleia-geral com 24,2\%.

Tabela 2

\section{Composição dos órgãos sociais (total e por sexo)}

\begin{tabular}{|c|c|c|c|c|c|c|c|c|c|c|c|c|c|c|c|}
\hline \multirow{3}{*}{$\begin{array}{l}\text { Dimensão } \\
\text { (n. }{ }^{\circ} \text { total } \\
\text { trabalhadores) }\end{array}$} & \multicolumn{5}{|c|}{$\begin{array}{c}\text { Mesa Assembleia } \\
\text { Geral }\end{array}$} & \multicolumn{5}{|c|}{$\begin{array}{c}\text { Órgãos } \\
\text { Administração }\end{array}$} & \multicolumn{5}{|c|}{$\begin{array}{c}\text { Órgãos } \\
\text { Fiscalizaçãa }\end{array}$} \\
\hline & \multicolumn{2}{|c|}{ M } & \multicolumn{2}{|c|}{$\mathrm{H}$} & \multirow{2}{*}{$\begin{array}{c}\text { Total } \\
\mathrm{n}\end{array}$} & \multicolumn{2}{|c|}{ M } & \multicolumn{2}{|c|}{ H } & \multirow{2}{*}{$\begin{array}{c}\text { Total } \\
n\end{array}$} & \multicolumn{2}{|c|}{ M } & \multicolumn{2}{|c|}{$\mathrm{H}$} & \multirow{2}{*}{$\frac{\text { Total }}{n}$} \\
\hline & $n$ & $\%$ & $n$ & $\%$ & & $n$ & $\%$ & $n$ & $\%$ & & $n$ & $\%$ & $n$ & $\%$ & \\
\hline 0 & 88 & 27,2 & 232 & 71,8 & 323 & 97 & 21,7 & 349 & 78,3 & 446 & 67 & 21,7 & 242 & 78,3 & 309 \\
\hline $1-9$ & 155 & 21,8 & 557 & 78,2 & 712 & 184 & 19,2 & 770 & 80,7 & 954 & 126 & 18,6 & 551 & 81,4 & 677 \\
\hline $10-24$ & 107 & 23,9 & 340 & 76,1 & 447 & 124 & 23,4 & 405 & 0,8 & 529 & 104 & 24,9 & 313 & 75,1 & 417 \\
\hline $25-49$ & 70 & 21,8 & 247 & 77,2 & 320 & 73 & 16,5 & 370 & 83,5 & 443 & 64 & 19,6 & 263 & 80,4 & 327 \\
\hline 50-99 & 53 & 25,4 & 156 & 74,6 & 209 & 109 & 33,0 & 221 & 67,0 & 330 & 76 & 21,4 & 139 & 64,6 & 215 \\
\hline $100-249$ & 33 & 37,1 & 56 & 62,9 & 89 & 41 & 28,3 & 104 & 71,7 & 145 & 24 & 27,3 & 64 & 72,7 & 88 \\
\hline + de 250 & 5 & 35,7 & 9 & 64,3 & 14 & 5 & 25,0 & 15 & 75,0 & 20 & 4 & 28,6 & 10 & 71,4 & 14 \\
\hline Total & & 1 & 1.5 & 97 & 2.108 & & 33 & & 34 & 2.867 & 46 & 55 & & 582 & 2.047 \\
\hline
\end{tabular}

Fonte: autoras - Base de Dados exercício de 2017 das cooperativas portuguesas. 
$\mathrm{Na}$ tabela 3 revela-se a existência de um número muito significativo de 230 cooperativas $(30,7 \%)$ com uma representação nula de mulheres nos órgãos sociais, comparativamente com apenas 2 cooperativas $(0,3 \%)$ que não contam com a presença de nenhum homem nos seus órgãos dirigentes. Assim, a maior frequência do número de mulheres, nas cooperativas portuguesas, para o ano de 2017, é de zero, seguindo-se praticamente, por ordem crescente, conforme se pode observar na tabela 5, de apenas 1 mulher na totalidade dos três órgãos sociais ( $n=162$, correspondendo a $21,6 \%)$, correspondendo à maioria da realidade nacional. Com efeito, se juntarmos o número de cooperativas sem qualquer elemento feminino nos seus órgãos sociais com aquelas que apenas contam com uma mulher, verificamos que totalizam $52,3 \%$ das cooperativas em análise.

Tabela 3

Frequência de cooperativas com mulheres nos órgãos sociais

\begin{tabular}{c|rc}
\hline \multirow{2}{*}{$\begin{array}{c}\text { N. de mulheres na totalidade da composição } \\
\text { dos 3 órgãos sociais }\end{array}$} & \multicolumn{2}{|c}{ Cooperativas } \\
\cline { 2 - 3 } 0 & 230 & $\%$ \\
1 & 162 & 30,7 \\
2 & 119 & 15,9 \\
3 & 81 & 10,8 \\
4 & 43 & 5,7 \\
5 & 29 & 3,9 \\
6 & 27 & 3,6 \\
7 & 22 & 2,9 \\
8 & 19 & 2,5 \\
9 & 7 & 0,9 \\
10 & 4 & 0,5 \\
11 & 2 & 0,3 \\
12 & 1 & 0,1 \\
13 & 1 & 0,1 \\
14 & 0 & 0,0 \\
15 & 0 & 0,0 \\
16 & 0 & 0,0 \\
17 & 2 & 0,3 \\
\hline Total & 749 & 100,0 \\
\hline
\end{tabular}

Fonte: autoras - Base de Dados exercício de 2017 das cooperativas portuguesas. 


\section{Conclusões}

Há uma conexão profunda e íntima entre o regime jurídico das cooperativas, que se baseia num conjunto de princípios e valores definidos pela Aliança Cooperativa Internacional e que integram o conceito de identidade cooperativa, e a igualdade de género.

Deste conceito de identidade cooperativa, resulta a afirmação de um ideal democrático de igualdade, que contraria o estabelecimento de discriminações em função do género. A governação democrática, que carateriza as cooperativas, terá de ser representativa, pelo que se impõe um regime de representação equilibrada entre mulheres e homens nos órgãos de administração e de fiscalização das cooperativas.

No entanto, os dados fornecidos pelo Portal de Credenciação da CASES evidenciam um desequilíbrio na representação dos homens e mulheres nos órgãos das cooperativas.

Torna-se, assim, necessário construir uma igualdade material ou fática que diminua a distância entre a igualdade formal e a igualdade real no acesso aos órgãos de administração e fiscalização das cooperativas.

Neste sentido, deverá discutir-se a necessidade de adoção pelas cooperativas, por via estatutária ou regulamentar, ou através da elaboração de planos para a igualdade, de medidas positivas, tais como as quotas de género, que acelerem a democracia paritária, assegurando uma representação equilibrada de homens e mulheres nos órgãos de administração e de fiscalização das cooperativas.

\section{Bibliografia}

Canotilho, G. \& Moreira, V., Constituição da República Portuguesa anotada, vol. I, Coimbra, Coimbra Editora, 2007.

FertuZINHOS, S., «Fundamentos constitucionais da igualdade de género», Sociologia, Problemas e Prática, 2016, pp.49-70.

$\mathrm{FICl}, \mathrm{A}$. , "Cooperative Identity and the Law», European Business Law Review, n. ${ }^{\circ} 24,2013$, pp. 37-64.

FICI, A., «Chapter 1. Definition and Objetives of Cooperatives», In Fajardo,G., Fici, A., Henrÿ, H., Hiez, D., Meira, D., Münkner, H., and Snaith, I., Principles of European Cooperative Law. Principles, Commentaries and National Reports, Cambridge, Intersentia, pp. 19-45.

Gaminde EGIA, E., «Las altas de los/as socios en las sociedades cooperativas», Boletín de la Asociación de Derecho Cooperativo, n. ${ }^{\circ}$ 51, 2016, pp.191208.

HIEZ, D., Coopératives. Création, Organisation, Fonctionnement, Éditions Delmas, Daloz, 2013. 
Leite, J.S., Princípios Cooperativos, Lisboa, Imprensa Nacional Casa da Moeda, 2012.

Martínez León, I.M.; Arcas Lario, N. \& García Hernández, M., «La influencia del género sobre la responsabilidad social empresarial en las entidades de economía social», REVESCO, n. 105, 2011, pp. 143-172.

MeIRA, D.A., «O quadro jurídico-constitucional do cooperativismo em Portugal», Cooperativismo e Economía Social, n. ${ }^{\circ} 33,2011$, pp. 31-46.

MeIRA, D., "Cooperative social responsibility: A Intercultural Analysis», in Clara Sarmento (ed.), In Permanent Transit. Discourses and Maps of the Intercultural Experience, Cambridge Scholars Publishing, 2012, pp. 127-144.

MEIRA, D.A., «Reflexões em torno do regime jurídico da reserva de educação e formação cooperativas», In Ferraz Teixeira, M. \& Ferraz Teixeira, M. (eds.), O Pensamento Feminino na Construção do Direito Cooperativo, Brasília, Vincere Editora, pp. 57-72.

MeIRA, D.A. \& Ramos, M.E., Governação e regime económico das cooperativas: estado da arte e linhas de reforma, Vida Económica, Porto, 2014.

MEIRA, D.A. \& RAMOS, M.E., «Os princípios cooperativos no contexto da reforma do Código Cooperativo português», CIRIEC-España, Revista jurídica de economía social y cooperativa, N. ${ }^{\circ} 27,2015$, pp. 401-428.

MeirA, D. \& Ramos, M.E., «Lei Basilar das Cooperativas. Memórias de uma lei precursora e contraditória«, ROA, Ano 77, 2017, pp. 61-91.

MöLls, S.H. \& STEHR, A., "Control of success, monitoring and evaluation when spreading the message of the Blueprint», in S. H. MÖLLS, HANS-H. MÜNKNER (eds.), ICA Blueprint for a Co-operative Decade - a Critical Anallysis, Nomos, Marburg, 2015, pp. 93-111.

MORENO, J.L., «Los valores según la Alianza Cooperativa Internacional $(\mathrm{ACl})$ », CIRIEC-España, Revista Jurídica de Economía Social y Cooperativa, n. ${ }^{\circ} 25$, 2014, pp. 371-393.

MünCKNeR, H.H., Nueve Lecciones de Derecho Cooperativo, Friedrich Ebert-Stiftung, Marburg, 1982.

Münkner, H.-H., Co-operative Principles and Co-operative Law, 2nd, revised edition, Lit Verlag GmbH \& Co. KG Wien, Zurich, 2015.

Namorado, R., Os Princípios Cooperativos, Coimbra, Fora do Texto, 1995.

Namorado, R., As Cooperativas. Empresas que não são Associações, Faculdade de Economia da Universidade de Coimbra, 1999.

Ribas Bonet, M.A. \& SAJARDo Moreno, A, «La desigual participación de hombres y mujeres en la economía social: teorías explicativas», CIRIEC-España, Revista de Economía Pública, Social y Cooperativa, n. ${ }^{\circ}$ 50, 2004, pp. 77-103.

SENENT VIDAL, M. José, "¿Cómo pueden aprovechar las cooperativas el talento de las mujeres? Responsabilidad social empresarial e igualdad real», Revesco, n. ${ }^{\circ} 105,2011$, pp.57-84.

SENENT VIDAL, M.J., "Aspectos de la perspectiva de género en la regulación jurídica de las cooperativas», In Ferraz Teixeira, M. \& Ferraz Teixeira, M. (eds.), O Pensamento Feminino na Construção do Direito Cooperativo, Brasília: Vincere Editora, pp. 227-246. 
VARGAS VASSEROT, C., «El principio cooperativo de puertas abiertas (Adhesión voluntaria y abierta). Tópico o realidad en la legislación y en la práctica societária», CIRIEC. Revista Jurídica de Economía Social y Cooperativa, n. ${ }^{\circ} 27$, 2015, pp.133-173.

ZuRdo, R.P.; García Centeno, C.; Gutiérrez Fernández, M. \& Fernández Barberis, G., «Responsabilidad social corporativa y género en los consejos de administración de las cooperativas de crédito españolas», Prisma Social, n. ${ }^{\circ} 10$, junio-noviembre, 2013, pp. 332-360. 